\title{
REVIEW \\ NICU discharge planning and beyond: recommendations for parent psychosocial support
}

\author{
IB Purdy ${ }^{1}$, JW Craig ${ }^{2}$ and P Zeanah ${ }^{3}$
}

\begin{abstract}
Parents will interact with a multitude of teams from various disciplines during their child's admission to the neonatal intensive care unit. Recognition of the emotional stressors experienced by these parents is a first step in working to provide the crucial support and parenting skills needed for bonding and caring for their infant from admission through discharge and beyond. Family-centered care involves time-sensitive two-way communication between parents and the multidisciplinary team members who coordinate care transition by providing emotional, educational, medical and home visitor support for these families. To do this well, a thoughtful exchange of information between team members and parents is essential to identify psychosocial stress and ameliorate family concerns. Parents will need emotional and educational support and follow-up resources. Establishing individualized, flexible but realistic, pre- and post-discharge plans with parents is needed to start their healthy transition to home and community.
\end{abstract}

Journal of Perinatology (2015) 35, S24-S28; doi:10.1038/jp.2015.146

\section{INTRODUCTION}

Parents naturally experience many kinds of stress after the birth of a baby. Stress can be amplified by many factors encountered during their baby's hospitalization in a neonatal intensive care unit (NICU), such as the baby's appearance and behavior, exposure to medical lingo, advanced technology and the risk of their baby dying. ${ }^{1}$ This stress leads to a variety of reactions, including sadness, fear, anger, anxiety, grief, depression and helplessness. ${ }^{2,3}$ Parents of NICU babies commonly experience high stress after discharge with costly medical bills for childbirth and NICU hospitalization. ${ }^{4,5}$ Non-medical expenses related to loss of work, decreased income and limited job alternatives can also be sources of stress. ${ }^{4,5}$ The costs of caring for premature infants after discharge are not just financial but also emotional. ${ }^{6,7}$ Factors that drive emotional conflicts and undermine parents' involvement include a lack of family-centered care, inadequate communication between staff and unwillingness for staff to alter their work regimen to meet parents' schedules. ' Some parents become overwhelmed after discharge by their baby's health problems, rescheduling appointments or seeing doctors unfamiliar with their baby's history and condition. $^{5}$

The primary focus of NICU personnel has been trying to improve the survival and neuromorbidity of high-risk infants. ${ }^{1,8-10}$ By contrast, there has been a lack of attention given to parents' psychosocial needs. As NICU infants and parents make up the family unit, the emphasis needs to broaden to include better psychosocial support for NICU parents with a goal toward improving developmental outcomes of the infants as well as the family's functioning., ${ }^{9} 11,12$ Teams of interdisciplinary, multidisciplinary and trans-disciplinary specialists need to unite to standardize best practices in discharge to prepare families for transition from NICU to home. Embracing dynamics of team collaboration ensures each family will receive state-of-the-art services in the NICU, during the transition to home and through the first years of life. ${ }^{13,14}$ Optimal team collaboration may require system-level changes. NICU teams need expert personnel dedicated to handling the intricate medical and social needs of the family unit to better develop parent-infant relationships before the time of discharge. ${ }^{14}$ NICU staff communication should encourage family involvement to prevent or minimize parental separation that disrupts parent bonding during a critical period of brain organization.

The following recommendations are offered as a guide for providing (a) emotional support, (b) parenting education, (c) medical follow-up care and (d) home visitations. These recommendations are based on prior evidence and guidelines referenced herein. The recommendations are meant to be fluid and flexible. Recommendations are also offered to help institutions establish policies and protocols to better prepare families during the transition to home and beyond.

\section{EMOTIONAL SUPPORT}

Psychological distress in NICU parents is associated with a deteriorating cycle that disrupts the parent-infant relationship, leading to subsequent impairments in child development and reciprocal negative effects on parents. ${ }^{15}$ Many parents report that NICU nurses and doctors do not understand their emotional condition. ${ }^{16}$ Evidence suggests that NICU parents undergo emotional strain due to poor communication experiences with NICU staff. ${ }^{16}$ These difficulties include a disrupted relay of information between units and shifts, parents not welcomed on rounds, limited visitation times and restrictive touch practices. ${ }^{16}$ Lack of good communication contributes to parents feeling lonely, abandoned and an unwanted presence. ${ }^{16}$ High levels of emotional stress are reported by parents of premature infants. ${ }^{16-19}$ Screening

${ }^{1}$ Division of Neonatology, Department of Pediatrics, David Geffen School of Medicine, University of California at Los Angeles, Los Angeles, CA, USA; ${ }^{2}$ School of Occupational Therapy, Brenau University, Gainesville, GA, USA and ${ }^{3}$ Cecil Picard Center for Child Development and College of Nursing and Allied Sciences, University of Louisiana, Lafayette, LA, USA. Correspondence: Dr IB Purdy, Division of Neonatology, Department of Pediatrics, David Geffen School of Medicine, University of California at Los Angeles, 10833 Le Conte Avenue, MDCC Room B2-375, Los Angeles, CA 90095-1752, USA.

E-mail: ipurdy@mednet.ucla.edu

Received 9 September 2015; accepted 18 September 2015 
parents for emotional distress should be a high priority in the NICU along with providing parents access to resources, handouts and contact information for parent support organizations and mental health care providers. ${ }^{15-29}$

In particular, mothers of preterm infants experience greater rates of depression than mothers of term infants, which can adversely affect their parenting abilities. ${ }^{16}$ Maternal distress early in a child's life has long-term effects on child behavior. ${ }^{15}$ Generally children of depressed mothers do not fare well, regardless of socioeconomic status, and need close pediatric follow-up. ${ }^{16}$ The literature suggests that early educational services can mitigate the adverse effects of maternal distress and even the effects of poverty on infant outcomes. ${ }^{16}$ Fathers are also at risk for emotional distress. Some return to work while bearing the emotional duty of caring for the mother, newborn baby and other children. ${ }^{17}$ Involving parents in their baby's care is a crucial step toward empowering and enabling their competence and confidence as caregivers. This empowerment must begin in the NICU and should be continued into the home.

All pre- and post-natal health-care in-patient and outpatient settings should have staff trained to identify families at economic, social and psychological risk, as well as providing the appropriate referrals. ${ }^{27}$ Psychologists in NICU or in the community are well suited to provide a wide range of clinical and consultative services and should have a role in individual and family assessments. ${ }^{27}$ Research on postpartum depression (PPD) found improved outcomes when management and treatment occurred within the practices that conducted the screening. ${ }^{27}$ All providers should engage in family-centered care using staff who are trained and experienced in mental health care and psychological screening for stress, depression and other forms of emotional distress. ${ }^{27}$

Research identified inflammation as an underlying risk factor for depression and specifically PPD observed in new parents. ${ }^{30,31}$ However, breast milk feeding (BMF) can counter this inflammatory effect in mothers and improve stress and immunity. ${ }^{31}$ NICU staff should counsel parents about skin-to-skin care when the baby is stable. Professionals need to point out the vital role of family members in supporting BMF to improve stress, immunity and health outcomes. ${ }^{32,33}$ All perinatal and pediatric health-care workers should help parents establish pre- and post-discharge plans to overcome breastfeeding obstacles to decrease emotional distress. ${ }^{32,33}$ To sustain BMF from admission through infancy, professionals should help parents develop a BMF plan, access breast pumps and gain support from their family. ${ }^{32,33}$ Initiating family-based interventions such as skin-to-skin holding and BMF to support the developing parent-infant relationship can also alleviate known sources of stress in the parents once they take their baby home. ${ }^{18}$

\section{PARENTING EDUCATION}

NICU family-centered developmental care includes providing mentoring to parents at times that meet their schedules. Individualized encouragement is needed to prepare parents to assume the parenting role and feel capable of providing home medications, special feeds, changing tubes, ordering additional supplies and initiating cardiopulmonary resuscitation if needed. Hospitals need to have designated NICU staff to mentor parents. Additionally, health-care teams in NICU, outpatient and at-home visits should be skilled at observing and assessing parent-infant interactions so staff can empower parents to respond to their baby's cues to support bonding. Educational tools such as the Newborn Behavioral Observation Scale are useful for professionals to gain and assess these skills. ${ }^{34}$

NICU parents need help preparing for their baby's transition to home and for potential readmissions. ${ }^{19}$ In addition to working with parents at the bedside or in a classroom, videos and websites are convenient methods of enhancing parents' knowledge and decreasing their stress. ${ }^{26,35,36} \mathrm{~A}$ three-step randomized trial of 781 infant-parent dyads examined a longitudinal parenting intervention. The first intervention was offered at 1 month after birth via educational booklets and DVDs on infant sleep and cry patterns, medical causes, settling techniques and parent self-care. At 2 months parents received telephone consults, and at 3 months parents participated in a parent group. ${ }^{36}$ These interventions decreased mothers' postnatal depression symptoms and decreased infant sleep and cry problems in frequent feeder infants. ${ }^{36}$ Family-focused care coordination using a combination of methods such as mail, telephone or telehealth is needed for at-risk families of medically fragile infants.

Parents' stress may escalate when approached about appointments and insurance authorizations for their baby's post-NICU care. Simply providing parents with names, addresses and phone numbers of specialists is an inadequate and unsafe referral method that may jeopardize babies' health and create extra stress. One to two parents and/or members of the family should receive individualized mentoring with checklists and outlines to cover all necessary care and education. Parents should be given a discharge folder that includes all teaching handouts, medication sheets, growth charts, supplies, follow-up appointment dates with phone contacts and a copy of the discharge summary. For the transition from NICU to community services to be seamless, the contact information and dates of scheduled appointments for the primary care provider (PCP) and all post-discharge specialists should be clearly documented in the NICU discharge summary. Utilizing the hospital's procedures regarding the sharing of information, the PCP and subspecialists involved should receive a copy of relevant information or be able to access it via the electronic medical record. High-risk infant follow-up (HRIF) clinics and home visitors (HV) should also be included in these communications. To facilitate the transition process, a staff member from the PCP's office should meet with the family before discharge to gain familiarity with their needs and to establish a supportive relationship.

Table 1 outlines tasks to be completed in preparing parents for transitioning to home. Discussion of these tasks should be provided in a culturally and linguistically appropriate manner so parents will be able to show competence in infant caregiving before transition to home. ${ }^{6}$ To promote best practices and minimize stress, NICUs should establish policies that include members of the discharge team serving as 'parent champions' to guide the family through the maze of referrals and to preschedule initial appointments. ${ }^{9}$ Whenever possible, staff should communicate with parents as 'equals' and team members during all communications.

\section{MEDICAL FOLLOW-UP}

\section{Pre-discharge}

Ideally, transition planning involves NICU discharge (DC) preparation by teams and good communication that begins at admission and continues beyond discharge. Team transition planning includes identifying the degree of medical, psychosocial, environmental and financial readiness of the infant-family unit. ${ }^{9}$ Weekly NICU multidisciplinary DC team meetings should provide opportunities for discussing these risks and the family's perspectives. ${ }^{37}$ In one study, families who were unprepared for NICU discharge reported more problems post-discharge with infant feedings and lack of basic supplies (nipples, bottles, formula, diapers and so on). ${ }^{9}$ The DC team should confirm that each family receives a clearly written discharge plan. The plan should include prescheduled appointments and contact information to providers who accepted their child and insurance coverage so parents can connect with providers for questions before the first scheduled visit. ${ }^{38} \mathrm{~A}$ NICU point person needs to communicate information 
Table 1. Parent pre-discharge plan checklist

\begin{tabular}{ll}
\hline Technical parenting & Basic baby care \\
skills & Individualized special care (medications, \\
& oxygen, equipment, tube changes) \\
& Cardiopulmonary resuscitation \\
& Patient advocacy tips \\
& Red flag checklists
\end{tabular}

Home environment readiness

Order supplies and equipment needed at home

How and where to acquire provisions for special needs

Nurse assessment of home

Community resources

Car seat/bed use

Car seat tolerance for special needs babies Installation of car seat

High-risk infant behavior: normal or abnormal

Normal newborn behaviors

How normal newborns differ from sick or preterm infants

Abnormal newborn behavior

Anticipatory guidance plans

What to expect and what to do at homesleeping, crying, feeding

Parental mental health and self care

(sleep, eat, parent support groups, websites, professional referrals)

Plans for coping with and soothing infants Enriched environments

Family support services Pediatrician

Early intervention services (social worker, physical, occupational, speech and feeding therapists)

Lactation support services

High-risk infant follow-up clinics

Home visitors

Public health nurses

Women, infants and children (WIC)

Derived from Smith et al. ${ }^{9}$

regarding parental emotional distress to alert other providers and assure documentation in the discharge plan. ${ }^{15}$ NICU DC teams that coordinate infant-family care plans should be responsible for scheduling the first referrals to outpatient providers. ${ }^{21,26}$ The DC team should assist the parents with establishing post-discharge plans and referrals to lactation and feeding specialists, mental health providers, social workers, PCP, HRIF clinics, specialists, visiting nurses and other community resources. ${ }^{39-45}$ These referrals ensure that supportive care resources are in place at discharge. Going through the medical checklist with parents also has benefits of increasing parents' confidence and emotional preparedness.

\section{Post-discharge}

Health-care teams in NICU and outpatient settings should observe evidence-based recommendations from literature reviews, policy statements and statewide quality improvement projects for preand post-discharge and follow-up during early childhood. ${ }^{37-45}$ Trends in shortened NICU stays may decrease parent separation but can result in infants going home with unresolved medical problems. $^{23,24}$ Earlier NICU discharge of children with special health-care needs (CSHCN) leads to families needing closer and more frequent health-care follow-up..$^{37,38}$ Some state agencies mandate NICUs to provide HRIF programs to coordinate care of CSHCN, helping families bridge the gap between the NICU, home and the community. HRIF clinics are responsible for providing special medical, developmental, psychological and social assessments during the first 3 years of the baby's life. ${ }^{37-42}$ Similarly, a medical home model ideally provides accessible, coordinated, culturally effective, family-centered care for CSHCN. ${ }^{43,44}$ Due to lack of funding, this model has not been widely adopted. ${ }^{44}$ Specialty health-care teams should work in partnership with one another to optimize care and encourage strong parent-infant relationships. ${ }^{14}$

Many NICU graduates still have severe medical complications that impact growth and development, which can be a source of stress to parents caring for them at home. Nutritional screening using home baby scales and telephone consults to monitor growth to prevent failure to thrive (by advising families on nutritional and caloric adjustments) can decrease parent stress and improve patient outcomes. An important predictor of how the infant grows and develops after discharge is the quality of the infant's psychosocial environment and parent-infant relationship. ${ }^{10}$ In addition to growth, several factors influence infant outcomes (gestational age at birth, brain injuries, variations in care management, parent's socioeconomic status and maternal mental health). ${ }^{8}$ Table 2 presents parent challenges while in the NICU and during follow-up, potential barriers to success and examples of facilitators and resources for parents. Advising parents about the possible emotional challenges during their child's first year and what conditions increase the risk for hospital readmission may help diminish some stress when it occurs. ${ }^{45}$

\section{HV SERVICES}

Congress created the Maternal, Infant and Early Childhood Home Visiting Program to support voluntary, evidence-based HV services for at-risk pregnant women and parents with children up to prekindergarten. ${ }^{46}$ The focus and timing of HV varies and can cover pregnancy, labor and early child health. ${ }^{46,47}$ Nurses conducting HV assessments may augment other services by including screening for depression and anxiety and providing an additional level of emotional support to families via techniques such as 'listening visits'. ${ }^{24,25} \mathrm{HV}$ programs may be funded by community resources, federal or local grants or insurance companies, based on family income criteria and consent to participate..$^{20,47-52}$ Communitybased HV programs may provide financially eligible families with parenting education and support services before delivery.

During NICU admission, if a family is already involved with a HV program continued involvement should be encouraged. If peer mentors developed supportive relationships with families, then it is desirable for mentors to continue involvement after discharge, if both parties are willing. If not, then HVs by NICU nurses or therapists or other appropriate referrals can be made. The importance of continuity of care for the NICU baby during and after discharge has long been recognized by hospitals and community healthcare providers. $^{24}$

Nurses report success in providing lactation support to families in the home to meet the AAP guidelines for continued exclusive breastfeeding during the first 6 months of life. ${ }^{49-51}$ The provision of visiting nurses may be the best option and environment for breastfeeding issues and infant support. ${ }^{49,50}$ Visiting nurses were also identified as a viable means of securing high-quality patientcentered outcomes and found to be as effective and safe for initial patient encounters post-hospital discharge as traditional office visits. $^{52}$

HV programs vary in terms of their intensity, focus and resources; such services may be provided by other registered nurses, public health nurses, child development specialists or professionals with specialized training to provide education, guidance and assistance to families. ${ }^{24,25,48-51}$ Improving the parent-child relationship may counterbalance the distorted or aberrant parenting that may result when parents sense their 
Table 2. Resources for helping parents overcome barriers

\begin{tabular}{|c|c|c|}
\hline $\begin{array}{l}\text { Establish parent- } \\
\text { infant bond }\end{array}$ & $\begin{array}{l}\text { Socioeconomic and cultural } \\
\text { Short maternity leave } \\
\text { Far distances between home and hospital } \\
\text { Transportation and house costs and } \\
\text { conveniences } \\
\text { Medical NICU environment } \\
\text { Restrictive NICU visiting hours } \\
\text { Competing demands (children, work, school) } \\
\text { Emotional and mental distress }\end{array}$ & $\begin{array}{l}\text { Community transportation: Assists with trains, car pools, bus tickets and } \\
\text { taxis } \\
\text { Community housing: Houses, shelters, hotels, etc. } \\
\text { Child support: Child life, volunteers for play area } \\
\text { Food: Hospital cafeteria food pass, WIC } \\
\text { Communication: } 24-h \text { NICU telephone access } \\
\text { Family-friendly NICU environment: Skin on skin Kangaroo care for parents, } \\
\text { low light and noise } \\
\text { Psychosocial support resources: Utilize social workers, mental health } \\
\text { professionals, psychiatrists and psychologists to screen and refer for stress } \\
\text { and depression }\end{array}$ \\
\hline $\begin{array}{l}\text { Acquiring parenting } \\
\text { skills }\end{array}$ & $\begin{array}{l}\text { Communication (language, education level) } \\
\text { Lack of parental engagement } \\
\text { Difficulties establishing lactation and } \\
\text { breastfeeding } \\
\text { Insufficient human resources }\end{array}$ & $\begin{array}{l}\text { Interpreters: Available by phone or in-person } \\
\text { Educational materials: Provide written, video, website or bedside teaching } \\
\text { offered in parent's language and education level. Topics: self-care, anxiety, } \\
\text { depression, optimal parenting, normal versus abnormal infant behaviors, } \\
\text { health, hygiene, safety, illness prevention } \\
\text { Red flag checklists: Establish what, why, when, where and who to call for } \\
\text { emergency treatment } \\
\text { Parent support groups: Hospital or community, websites, referrals, parent } \\
\text { volunteers } \\
\text { Breastfeeding support: Lactation specialists, WIC, professionals trained to } \\
\text { meet the baby friendly hospital initiatives and AAP guidelines }{ }^{32}\end{array}$ \\
\hline $\begin{array}{l}\text { Discharge and } \\
\text { follow-up }\end{array}$ & $\begin{array}{l}\text { Health insurance } \\
\text { Administrative procedures for transfer of } \\
\text { care to community } \\
\text { Special equipment } \\
\text { Medications } \\
\text { Lack of access to specialized/ emergency } \\
\text { care in rural areas outside the city } \\
\text { Poor discharge follow-up coordination } \\
\text { system for families }\end{array}$ & $\begin{array}{l}\text { Parents advocate for patient safety: Children's Hospitals' Solutions-Patient } \\
\text { Safety website } 35 \\
\text { Pre-established discharge plans: NICU point personnel to identify family } \\
\text { needs to provide special training. Pre-schedule appointments, phone } \\
\text { contacts } \\
\text { Parent training check lists: Medication, feeding, special cares (tracheostomy, } \\
\text { gastrostomy tubes, wounds), equipment (oxygen, suction, ventilation) and } \\
\text { contact numbers to reorder supplies } \\
\text { NICU follow-up programs: Post-discharge primary care, HRIF teams, early } \\
\text { intervention and home visitor services for ongoing cares and support }\end{array}$ \\
\hline
\end{tabular}

child is vulnerable and/or have negative perceptions of the child. A systematic review of studies on HV offers evidence of some benefits to improved parent-infant interaction with preterm infants. ${ }^{48}$ Unfortunately, due to methodological limitations, these studies have not shown any benefit to infant development, abuse/ neglect, growth/nutrition or morbidity. ${ }^{48}$ Future research is needed to investigate potential benefits of HVs in medical cost savings or potential physiologic and psychological impact of positive parenting experiences. In particular, more research comparing HV with standard care for breastfeeding and PPD with other specific at-risk NICU populations is needed.

It is important that all health-care staff seek input and communication with other professionals and providers and community programs that are involved with these families. Postpartum Support International is one example of a worldwide network of support available across every American state and in 36 additional countries that offers training and access to care coordinators. ${ }^{53}$ Care coordination teams in NICU, HRIF, Medical Home, Primary Care and subspecialties should be knowledgeable about HV websites and availability of referrals to HV programs in their state to provide parents with assistance contacting these resources for help and to individualize referrals to resources that match family's needs.

\section{SUMMARY}

A concerted effort in understanding the continuum of parentinfant needs is essential to support healthy parent-infant relationships during the early years of the infant's life both within the NICU and post-discharge. ${ }^{6}$ A well-prepared family should receive anticipatory counseling about the psychological stresses that often occur throughout pregnancy and the first several years of life. Using a 'team working with teams' approach for discharge planning, the NICU professionals need to align with care coordination across disciplines. Working together, the care teams can help families build bridges from the NICU to the community. The ultimate goals for pre- and post-discharge care should be to communicate, identify, coordinate and refer families at-risk to appropriate mental health and psychosocial services before NICU discharge and while attending HRIF clinics, Primary Care Clinics, $\mathrm{HV}$ and other community programs. NICU teams handing off to community teams need updated evidence-based guidelines for recognition of potential barriers and facilitators to help parents be prepared to overcome obstacles and challenges to caring for themselves and their family.

\section{CONFLICT OF INTEREST}

The authors declare no conflict of interest.

\section{ACKNOWLEDGEMENTS}

This work was supported by the Wellness Network, Prolacta Bioscience, Loma Linda University Department of Pediatrics, University of California Los Angles Department of Pediatrics/Division of Neonatology, Brenau University, NICU Parent Support at Mercy Hospital in St Louis, MO, Hand to Hold, Preemie Parent Alliance, Zoe Rose Memorial Foundation, the Rosemary Kennedy Trust, and Eden's Garden. Many thanks to other participants from the National Perinatal Association Workgroup on Psychosocial Support of NICU Parents, including Jennifer Beatty, Barbara DeLoian, Erika Goyer, Nick Hall, Becky Hatfield, Heather McKinnis, Sharon Sprinkle and Elly Yost. 


\section{REFERENCES}

1 Lefkowitz DS, Baxt C, Evans JR. Prevalence and correlates of posttraumatic stress and postpartum depression in parents of infants in neonatal intensive care units (NICU). J Clin Psychol Med Settings 2010; 17: 230-237.

2 Joseph RA, Mackley AB, Davis CG, Spear ML, Locke RG. Stress in fathers of surgical neonatal intensive care unit babies. Adv Neonatal Care 2007; 7: 321-325.

3 Liu WF, Laudert S, Perkins B, Macmillan-York E, Martin S, Graven S. The development of potentially better practices to support the neurodevelopment of infants in the NICU. J Perinatol 2007; 27: S48-S74.

4 Wharam JF, Grave AJ, Kozhimannil KB. Navigating the rise of high-deductible health insurance. Childbirth in the bronze age. JAMA 2015; 313(3): 245-246.

5 Committee on Understanding Premature Birth and Assuring Healthy Outcomes Board on Health Sciences Policy. Behrman Richard E, Adrienne Stith Butler (eds). National Academy of Sciences, National Academic Press: Washington, DC, 2007.

6 Craig J. The Neonatal Intensive Care Unit (NICU): Self-Efficacy of Caregiving and the Lived Experience of Parents Post-NICU Discharge. Fielding Graduate University: Santa Barbara, CA, USA, 2015.

7 Melnyk B, Crean H, Feinstein N, Fairbanks E. Maternal anxiety and depression after a premature infant's discharge from the neonatal intensive care unit: explanatory effects of the creating opportunities for parent empowerment program. Nurs Res 2008; 57(6): 383-394.

8 Purdy I, Melwak M. Who is at risk? High risk infant follow-up. Newborn Infant Nurs Rev 2012; 12(4): 221-226.

9 Smith VC, Hwang SS, Dukhovy D, Young S, Pursley DM. Neonatal intensive care unit discharge preparation, family readiness and infant outcomes: connecting the dots. J Perinatol 2013; 33: 415-421.

10 Taylor HG, Klein N, Hack M. School-age consequences of birth weight less than 750 g: a review and update. Dev Neuropsychol 2000; 17: 289-321.

11 Thomson G, Moran V, Axelin A, Dykes F, Flacking R. Integrating a sense of coherence into the neonatal environment. BMC Pediatr 2013; 13: 84.

12 Klassen A, Lee S, Raina P, Lisonkova S. Psychosocial health of family caregivers of children admitted at birth to a NICU and healthy children: a population-based cross-sectional survey. BMC Pediatr 2004; 4: 24.

13 Barbosa VM. Teamwork in the neonatal intensive care unit. Phys Occup Ther Pediatr 2013; 33(1): 5-26.

14 Ohlinger J, Brown MS, Laudert S, Swanson S, Fofah O. Development of potentially better practices for the neonatal intensive care unit as a culture of collaboration: communication, accountability, respect, and empowerment. Pediatrics 2003; 111: 3471-3481.

15 Hynan M, Mounts K, Vanderbilt D. Screening parents of high-risk infants for emotional distress: rationale and recommendations. J Perinatol 2013; 33(10): 748-753.

16 Zuckerman BS, Beardslee WR. Maternal depression: a concern for pediatricians. Pediatrics 1987; 79: 110-117.

17 Mackley $A B$, Spear ML. Forgotten parent: NICU paternal emotional response. Adv Neonatal Care 2010; 10(4): 200-203.

18 Wigert H, Dellenmark MB, Bry K. Parents' experiences of communication with neonatal intensive-care unit staff: an interview study. BMC Pediatr 2014; 14: 304.

19 Browne J, Ayelet Talmi A. Family-based intervention to enhance infant parent relationships in the neonatal intensive care unit. J Pediatr Psychol 2005; 30: 667-677.

20 Singer LT, Fulton S, Davillier M, Koshy D, Salvator A, Baley JE. Effects of infant risk status and maternal psychological distress on maternal-infant interactions during the first year of life. J Dev Behav Pediatr 2003; 24: 233-241.

21 National Perinatal Association's Family Advocacy Network. Available at www. nationlperinatal.org/parentsupportgroups.

22 Preemie Parent Alliance. Available at http://preemieparentalliance.weebly.com/\#/.

23 The European Foundation for the Care of Newborn Infants. Available at www. efcni.org.

24 Parents as Teachers. Available at www.parentsasteachers.org.

25 Nurse Family Partnership. Available at www.nursefamilypartnership.org

26 The March of Dimes Caring for your Baby, 2015. Available at www.marchofdimes. org/baby/caring-for-baby-library.aspx.

27 Earls MF. The Committee on Psychosocial Aspects of Child and Family Health Incorporating recognition and management of perinatal and postpartum depression into pediatric practice. Pediatrics 2010; 126: 1032-1039.

28 Musser AK, Ahmed AH, Foil KJ, Coddington JA. Paternal postpartum depression: what health care providers should know. J Pediatr Health Care 2013; 27: 479-485.

29 Gerstein E, Poehlmann-Tynan J, Clark R. Mother-child interactions in the NICU: relevance and implications for later parenting. J Pediatr Psychol 2015; 40: 33-44.

30 Kendall-Tackett K. A new paradigm for depression in new mothers: the central role of inflammation and how breastfeeding and anti-inflammatory treatments protect maternal mental health. Int Breastfeed J 2007; 2: 6.
31 Groer MW, Davis MW. Cytokines, infections, stress, and dysphoric moods in breastfeeders and formula feeders. J Obstet Gynecol Neonatal Nurs 2006; 35: 599-607.

32 American Academy of Pediatrics Policy Statement. Breastfeeding and the use of human milk. Pediatrics 2012; 129: e827-3841.

33 Purdy I, Singh N, Le C, Bell C, Whiteside C, Collins M. Biophysiologic and social stress relationships with breast milk feeding pre- and post-discharge from the neonatal intensive care unit. J Obstet Gynecol Neonatal Nurs 2012; 41: 347-357.

34 Nugent J, Keefer C, Minear S, Johnson L, Blanchard Y. Forward by T Brazelton. Understanding Newborn Behavior and Early Relationships: The Newborn Behavioral Observations (NBO) System Handbook. Brookes Publishing: Baltimore, MD, USA, 2007.

35 Children's Hospitals' Solutions for Patient Safety. Be Part of the Safety Team for Your Child. Available at www.solutionsforpatientsafety.org/.

36 Hiscock H, Cook F, Bayer J, Le HND, Mensah F, Cann W et al. Preventing early infant sleep and crying problems and postnatal depression: a randomized trial. Pediatrics 2015; 133: e346-e354.

37 American Academy of Pediatrics Committee on Fetus and Newborn. Policy Statement: Hospital discharge of the high-risk neonate. Pediatrics 2008; 122(5): 1119-1126.

38 Bockli K, Andrews B, Pellerite M, Meadow W. Trends and challenges in United States neonatal intensive care units follow-up clinics. J Perinatol 2014; 34: 71-74.

39 Kuppala VS, Tabangin M, Haberman B, Steichen J, Yolton K. Current state of highrisk infant follow-up care from the United States: results of a national survey of academic follow-up programs. J Perinatol 2012; 32: 293-298.

40 American Association of Pediatrics. Follow-up care of high-risk infants. Pediatrics 2004; 114: 1377-1397.

41 Raffray M, Semenic S, Galeano SO, Marin S. Barriers and facilitators of preparing families with premature infants for discharge home from the neonatal unit. Perceptions of health care providers. Invest Educ Enferm 2014; 32: 379-392.

42 Department of Health and Children Services, California Children's Services HRIF Program. Available at http://www.dhcs.ca.gov/services/ccs/Pages/HRIF.aspx.

43 American Association of Pediatrics. The medical home. Pediatrics 2004 113(5) Part 2 1545-1548.

44 Van Cleave J, Boudreau A, McAllister J, Cooley C, Maxwell A, Kuhthau K. Care Coordination over time in Medical Homes for children with special health care needs. Pediatrics 2015; 135(6): 1018-1026.

45 Placentia FX, McCullough LB. Biopsychosocial risks of parental care for high-risk neonates: implications for evidence-based parental counseling. J Perinatol 2012; 32: $381-386$.

46 Health Resources and Services Administration Maternal, Infant and Early Childhood Home Visitation Program Partnering with Parents to Help Children Succeed, 2015. Available at www.mchb.hrsa.gov/programs/homevisiting

47 US Department of Health and Human Resources, Administration for Children and Families, Home Visiting Evidence of Effectiveness (HomeVee). 2015. Available at http://homvee.acf.hhs.gov.

48 Goyal N, Teeters A, Ammerman R. Home visiting and outcomes of premature infants: a systematic review. Pediatrics 2013; 32: 502-516.

49 Parker C, Warmuskerken G, Sinclair L. Enhancing neonatal wellness with home visitation. Nurs Womens Health 2015; 19: 37-41.

50 Dodge KA, Goodman WB, Murphy RA, O'Donnell K, Sato J. Randomized controlled trial of universal postnatal nurse home visiting: impact on emergency care. Pediatrics 2013; 132: S140-S146.

51 American Academy of Pediatrics and American College of Obstetricians and Gynecologists. Perinatal Guidelines for Home Visitation. American Academy of Pediatrics and American College of Obstetricians and Gynecologists: Washington, DC, USA, 2010.

52 Paul IM, Beiler JS, Schaefer EW, Hollenbeak CS, Alleman N et al. A randomized trial of single home nursing visits versus office-based care after nursery/maternity discharge: the Nurses for Infants Through Teaching and Assessment After the Nursery (NITTANY) Study. Arch Pediatr Adolesc Med 2012; 166: 263-270.

53 Postpartum Support International. Available at www.postpartum.net.

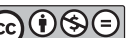

This work is licensed under a Creative Commons AttributionNonCommercial-NoDerivs 4.0 International License. The images or other third party material in this article are included in the article's Creative Commons license, unless indicated otherwise in the credit line; if the material is not included under the Creative Commons license, users will need to obtain permission from the license holder to reproduce the material. To view a copy of this license, visit http:// creativecommons.org/licenses/by-nc-nd/4.0/ 